\title{
Effect of exercise doses on functional recovery in neonatal brachial plexus palsy: A randomized controlled study
}

\author{
(D) Nilay Sahin, ${ }^{1}$ (1) Ali Yavuz Karahan ${ }^{2}$ \\ ${ }^{1}$ Department of Physical Therapy and Rehabilitation, Balikesir University Faculty of Medicine, Balikesir, Turkey \\ 2Department of Physical Therapy and Rehabilitation, Usak University Faculty of Medicine, Usak, Turkey
}

\begin{abstract}
OBJECTIVE: The aim of this study was to examine how much recovery upper obstetric brachial plexus palsy (OBPP) patients showed with exercises when they were 3, 6, and 12 months old and to evaluate whether the exercise treatment given at different frequencies contributes to this recovery or not.

METHODS: This study was designed as a randomized controlled trial. Sixty cases who were referred to Pediatric Rehabilitation and Pediatric Orthopedic Clinics with the diagnosis of having Groups I and II OBPP according to Narakas classification were included in the study. Subjects were randomly divided into two treatment groups. The first group had intense exercise program 3 times daily, and the second group had a standard exercise program once in a day. The subjects were assessed using a passive-active range of motion (ROM) and hospital for sick children muscle grading system at their first clinic visit and every month after until they became 12 months old.

RESULTS: In both groups, a significant recovery was observed in ROM and muscle strength of all movements of the shoulder, elbow flexion, and forearm supination at the $3^{\text {rd }}, 6^{\text {th }}$, and $12^{\text {th }}$-month reassessments, whereas a significant difference was not achieved on both parameters between two groups.

CONCLUSION: According to the results, exercise frequency did not affect the recovery rate and results in the cases with OBPP and exercises were influential against possible complications that may occur.

Keywords: Brachial plexus lesion; exercise; functional recovery; muscle strength.

Cite this article as: Sahin N, Karahan AY. Effect of exercise doses on functional recovery in neonatal brachial plexus palsy: A randomized controlled study. North Clin Istanb 2019;2019;6(1):1-6.
\end{abstract}

$\mathrm{O}^{\mathrm{s}}$ bstetric brachial plexus palsy (OBPP) is a flaccid paralysis mostly seen on arm due to the injury of brachial plexus during birth. It occurs as a result of distention and tear in the body of brachial plexus and avulsion of spinal roots $[1,2]$. At every 1000 birth, OBPP incidence is $0.3-1.56 \%$, recovery rate is $84 \%$, and permanent damage rate is $0.5-25 \%$. Hence, OBPP is an important neonatal morbidity cause [3-5]. The most observed form of OBPP is the involvement of upper brachial plexus (C5-6-7). In C5-6 injuries, shoulder abductors, internal rotators, and forearm flexor muscles are mostly affected, and the decline in forearm supination movement can be seen, but hand functions are retained. If an injury to $\mathrm{C} 7$ is added, then triceps and wrist extensors are also affected $[4,6,7]$.

Although an enough spontaneous recovery to use extremity functionally can be gained in most of the upper OBPP patients, all these patients are given an exercise program at the first stage. $[2,8-10]$. The aim to give exercises is mostly to prevent contracture formation and

Received: July 08, 2017 Accepted: December 28, 2017 Online: August 07, 2018

Correspondence: Dr. Ali Yavuz KARAHAN. Usak Universitesi Tip Fakultesi, Fiziksel Tedavi ve Rehabilitasyon Anabilim Dali, 64200 Usak, Turkey.

Tel: +902762212233 e-mail: ayk222@hotmail.com

(c) Copyright 2018 by Istanbul Provincial Directorate of Health - Available online at www.northclinist.com 
to avoid muscle imbalance $[4,7]$. There are no accurate data on the effect of any particular exercise which is more than the other, or one has additional effects on recovery than others to prevent complication; besides, there is no consensus on what frequency, intensity, or duration should exercise therapy be given. While some authors claimed that exercises do not have any effect on the recovery of the patients, others suggested that exercises could contribute to recovery by positively affecting regenerative process [4].

It was hypothesized that intense exercise programs given in cases with peripheral nerve or spinal cord injury may accelerate recovery by contributing to plasticity development [11-13]. When no improvement is gained in biceps muscle function in patients with OBPP in the first 3 months during follow-up, shoulder dysfunction or residual upper extremity incapability often develops. Therefore, some researchers recommend going further to surgical interventions in cases that recovery is not observed in biceps muscle function within 3-6 months [9]. Therefore, the aim of this study was to examine how much recovery upper OBPP patients showed with exercises when they were 3,6 , and 12 months old and to evaluate whether the exercise treatment given at different frequencies contributes to this recovery or not.

\section{MATERIALS AND METHODS}

This study conducted in Physical Medicine and Rehabilitation Department of Balikesir University between June and December 2014. The study was approved by the local research ethics committee of Selcuk University's Faculty of Medicine (No: 276/2014). Written informed consent was obtained from parents of all patients for being included in the study. 60 cases that were referred to Pediatric Rehabilitation and Pediatric Orthopedic Clinics with the diagnosis of Groups I and II OBPP according to Narakas classification were included in the study following a multidisciplinary approach, physical examination, and electromyography (EMG) assessments. The patients in Groups III and IV according to Narakas classification 2 and the ones who had another comorbid neurological problem, contracture, and/or fracture on the affected arm were excluded from the study. The parents of patients were elucidated with precise information about the study, and all of them signed approval forms.

Sixty patients were divided into two groups randomly (for the randomization-allocation concealment, all the randomization numbers were concealed in separate envelopes and marked by the patient number on the outer envelope. For randomization, the patients admitted into the program were divided into groups); the first group had intense exercise program 3 times daily (intensive exercise group [IEG] as a Group I), and the second group defined as a control group and had a standard exercise program once in a day (EG as Group II).

\section{Exercise program}

Passive range of motion (ROM) exercises were given to all joints of the upper extremities at first, and in the following months, active ROM and muscle enhancement exercises (according to the cooperation level of the children) were started. The duration time of exercises was related to the children's cooperation. Since biceps muscle force of 3 patients in the Group 1 and 1 patient in the Group II was weak, they were excluded from the study. The subjects were assessed using passive-active ROM degrees and hospital for sick children muscle grading system on their first clinic visit and every month after until they became 12 months old [5].

\section{Assessment Criteria}

\section{Narakas classification}

This classification is composed of four groups: Group I C5-6 shoulder and biceps paralysis, Group II C5-7 paralysis of shoulder, biceps, and forearm extensors, Group III C5-Th1 complete paralysis of the extremity, and Group IV C5-Th1 complete paralysis of extremity accompanying Horner's syndrome [5].

\section{Range of motion}

ROM was evaluated both passively and actively with joint-specific movements: Shoulder ROM: Flexion, abduction, extension, and external/internal rotations; elbow ROM: Flexion, extension, supination, and pronation; and wrist ROM: Extension and flexion. Active ROM was measured on 3 different days following each other and calculated by averaging these measures by the same observer, which proved intraobserver reliability.

\section{Muscle testing}

Shoulder flexors and abductors, elbow flexor, and forearm supinator muscles were evaluated using hospital for sick children muscle grading system (Clarke and Curtis). This classification system is appropriate for children younger than 3 years old, which measures all joints without any commands. The hospital for sick children scale is not a "muscle grading system" but is an assessment of spontaneous active movement. There are seven stages totally, in 


\begin{tabular}{ll} 
TABLE 1. Hospital for sick children muscle grading system \\
\hline Observation & Muscle grade \\
\hline Gravity eliminated & 0 \\
No contraction & 1 \\
Motion $<1 / 2$ range & 2 \\
Motion $>1 / 2$ range & 3 \\
Full motion & 4 \\
Against gravity & \\
Motion $<1 / 2$ range & 5 \\
Motion $>1 / 2$ range & 6 \\
Full motion & 7
\end{tabular}

which the gravity is eliminated until stage 4 (Table 1 ).

The families were educated in the hospital by a talented physiotherapist with a 5-day oral, visual, and applied training program, in which the parents were then tested. The patients were examined and exercise programs were checked by the same physician every month until they became 12 months old. It was ordered to make the exercises 3 times daily for the IEG and once daily for the EG.

\section{Statistical Analysis}

Statistical evaluation was performed using SPSS 16 (SPSS Inc. Released 2007. SPSS for Windows, Version 16.0. Chicago, SPSS Inc.). The one-sample Kolmogorov-Smirnov test was applied for non-parametric values that comply with a normal distribution in innergroup assessments. Analysis of variance (ANOVA) was used in two-way repeated (time and groups) measurements to compare data from the parameters repeatedly measured in the inner group. In cases in which the variance analysis test result was significant, Bonferroni correction was performed to compare between groups as a post hoc test. The Bonferroni student $t$-test was used to detect different groups. The student $t$-test was used for independent groups to analyze data that complied with a normal distribution. $\mathrm{P}<0.05$ was considered to be statistically significant $(\mathrm{p}<0.05)$.

\section{RESULTS}

Since mean biceps muscle force of four patients was 1.42 when they were 4 months old, these children were referred to surgery and excluded from the study. Hence, a
TABLE 2. Characteristics of patients of obstetric brachial plexus palsy

$\begin{array}{lc}\text { Age (days) } & 7.50 \pm 5.18 \\ \text { Sex (male/female) } & 38 / 15 \\ \text { Weight (gr) } & 4388 \\ \text { Affected side (left/right) } & 42: 20\end{array}$

total of 62 patients ( 38 boys and 24 girls), with a mean age of $7.50 \pm 5.18$ days, were included in the study. The affected side was the left in 42 cases and right in 20 cases. All infants were born vaginally, and 52 cases had difficult labor history. The average birth weight was $4388 \mathrm{~g}$ (Table 2). $97 \%$ of the subjects were in Group I, while 3\% were in Group II according to Narakas classification.

Statistical analysis inside the groups: In terms of active ROM, while a statistically significant improvement was gained in both groups between $1^{\text {st }}-3^{\text {rd }}$ months, $3^{\text {rd }}$ $6^{\text {th }}$ months, and $6^{\text {th }}-12^{\text {th }}$ months in shoulder abduction, external rotation and flexion, and elbow flexion and forearm supination and between $1^{\text {st }}-3^{\text {rd }}$ months and $3^{\text {rd }}$ $6^{\text {th }}$ months in shoulder internal rotation and extension $(p<0.05)$; there was no significant difference in elbow extension, forearm pronation, and wrist extension since they already had nearly normal values at the beginning of the treatment $(p>0.05)$. Active ROM measures of the patients are shown in Table 3. There was a statistically significant improvement in the muscle strength in both groups between $1^{\text {st }}-6^{\text {th }}$ months and $6^{\text {th }}-12^{\text {th }}$ months in shoulder abduction, between $1^{\text {st }}-3^{\text {rd }}$ and $6^{\text {th }}-12^{\text {th }}$ months in shoulder flexion, and between $1^{\text {st }}, 3^{\text {rd }}, 6^{\text {th }}$, and $12^{\text {th }}$ months in elbow flexion and forearm supination $(\mathrm{p}<0.05)$ (Table 4).

Statistical analysis between the groups: No statistically significant improvement was observed between the groups in EMP measures and muscle force assessments $(\mathrm{p}>0.05)$.

\section{DISCUSSION}

In upper brachial plexus OBPP patients, there was no significant difference between the groups who had intensive exercise program and those who did not. Only four of the cases were further referred to surgery. In all the cases except for these four cases, good arm functions were observed while they were 3 months old, and nearly normal functions were found while they were 12 months 
TABLE 3. Measurements of active range of motion in patients with obstetric brachial plexus palsy

\begin{tabular}{|c|c|c|c|c|c|c|c|c|}
\hline & \multicolumn{2}{|c|}{ Birth } & \multicolumn{2}{|c|}{3 months } & \multicolumn{2}{|c|}{6 months } & \multicolumn{2}{|c|}{12 months } \\
\hline & Group I & Group II & Group I & Group II & Group I & Group II & Group I & Group II \\
\hline \multicolumn{9}{|l|}{ Shoulder $\left({ }^{\circ}\right)$} \\
\hline Abduction & $11.92(4.38)$ & $12.82(3.63)$ & $38.71(3.38)^{*}$ & $38.04(3.61)^{\ddagger}$ & $62.92(2.46)^{*}$ & $62.82(2.53)^{\ddagger}$ & $87.63(2.53)^{*}$ & $87.40(2.55)^{\ddagger}$ \\
\hline External rotation & 0 & 0 & $18.07(2.46)^{*}$ & $18.03(2.24)^{\ddagger}$ & $23.92(2.48)^{*}$ & $23.47(2.35)^{\ddagger}$ & $28.20(2.42)^{*}$ & $28.04(2.49)^{\ddagger}$ \\
\hline Extension & 0 & 0 & $18.84(2.13)^{*}$ & $17.60(2.55)^{\ddagger}$ & $22.15(2.13)^{*}$ & $22.17(2.53)^{\ddagger}$ & $22.53(2.33)^{*}$ & $22.04(2.38)^{\ddagger}$ \\
\hline Flexion & $19.87(3.34)$ & $19.13(3.88)$ & $51.53(2.33)^{*}$ & $51.39(2.55)^{\ddagger}$ & $66.53(2.33)^{*}$ & $65.43(2.21)^{\ddagger}$ & $83.58(2.27)^{*}$ & $82.60(2.45)^{\ddagger}$ \\
\hline \multicolumn{9}{|l|}{ Elbow $\left({ }^{\circ}\right)$} \\
\hline Flexion & 0 & 0 & $68.07(2.46)^{*}$ & $67.60(2.55)^{\ddagger}$ & $77.92(2.46)^{*}$ & $77.39(2.54)^{\ddagger}$ & $102.82(4.55)^{*}$ & $102.78(5.10)^{\ddagger}$ \\
\hline Extension & $103.07(4.67)$ & $103.47(4.86)$ & $115.89(4.98)^{*}$ & $115.65(5.06)^{\ddagger}$ & $118.46(3.65)^{*}$ & $117.82(4.21)^{\ddagger}$ & $118.46(3.65)^{*}$ & $117.82(4.21)^{\ddagger}$ \\
\hline \multicolumn{9}{|l|}{ Wrist $\left(^{\circ}\right)$} \\
\hline & $81.79(2.42)$ & $81.52(2.35)$ & $88.20(2.42)^{*}$ & $88.47(2.35)^{\ddagger}$ & $88.20(2.42)^{*}$ & $88.47(2.35)^{\ddagger}$ & $88.20(2.42)^{*}$ & $88.47(2.35)^{\ddagger}$ \\
\hline Flexion & $71.46(2.33)$ & 71.95 (2.49) & $71.46(2.33)^{*}$ & $71.95(2.49)^{\ddagger}$ & $71.46(2.33)^{*}$ & $71.95(2.49)^{\ddagger}$ & $71.46(2.33)^{*}$ & $71.95(2.49)^{\ddagger}$ \\
\hline
\end{tabular}

*: Statistically significant differences according to the Birth value inner Group I evaluations $(p<0.05)$. *: Statistically significant differences according to the Birth value inner Group II evaluations $(p<0.05)$. $p>0.05$ for each between group evaluations; $\left({ }^{\circ}\right)$ : Degree of movement at a joint.

TABLE 4. Hospital for Sick Children muscle grading system in patients with obstetric brachial plexus palsy

\begin{tabular}{|c|c|c|c|c|c|c|c|c|}
\hline & Group I & Group II & Group I & Group II & Group I & Group II & Group I & Group II \\
\hline \multicolumn{9}{|l|}{ Shoulder } \\
\hline Abduction & $3.50(0.46)$ & $3.52(0.51)$ & $4.07(0.57)^{*}$ & $4.01(0.73)^{\ddagger}$ & $5.51(0.50)^{*}$ & $5.56(0.50)^{\ddagger}$ & $6.64(0.48)^{*}$ & $6.56(0.50)^{\ddagger}$ \\
\hline Flexion & $3.61(0.49)$ & $3.65(0.48)$ & $5.40(0.46)^{*}$ & $5.47(0.51)^{\ddagger}$ & $5.43(0.48)^{*}$ & $5.48(0.52)^{\ddagger}$ & $6.46(0.42)^{*}$ & $6.30(0.47)^{\ddagger}$ \\
\hline Flexion & $0.56(0.50)$ & $0.52(0.51)$ & $4.71(0.64)^{*}$ & $4.82(0.77)^{\ddagger}$ & $5.45(0.64)^{*}$ & $5.43(0.50)^{\ddagger}$ & $6.38(0.45)^{*}$ & $6.39(0.49)^{\ddagger}$ \\
\hline \multicolumn{9}{|l|}{ Forearm } \\
\hline Supination & $0.41(0.50)$ & $0.43(0.50)$ & $2.58(0.52)^{*}$ & $2.60(0.49)^{\ddagger}$ & $5.53(0.49)^{*}$ & $5.52(0.51)^{\ddagger}$ & $6.30(0.40)^{*}$ & $6.34(0.48)^{\ddagger}$ \\
\hline
\end{tabular}

*: Statistically significant differences according to the Birth value inner Group I evaluations $(p<0.05)$. $\neq$ : Statistically significant differences according to the Birth value inner Group II evaluations $(p<0.05)$. $p>0.05$ for each between group evaluations.

old. Hence, almost exact recovery was gained in $94 \%$ of the cases with OBPP in our study. The patients with OBPP at the C5-6 level, generally, display improvement in a period from 3 months to 9 months of age [3-5, 7]. It is reported that improvement period may continue until 12 months in some studies [5].
The diagnosis of OBPP is based on a precise physical examination with a support of EMG study. The valid parameters used to evaluate improvement in OBPP cases are ROM measurements, EMG studies, and Clarke and Curtis muscle classification system for children under the age of [3-5]. If a common development cannot 
be gained in the shoulder and biceps muscles while the child is in 3 months and 6 months old, then he/she is referred to surgery $[4,7]$. While $70-95 \%$ of the patients improve almost completely, $10 \%$ may require surgery $[4$, $7,14]$. Likely $6 \%$ of our subjects had operations, $94 \%$ displayed a nearly complete improvement between 6 and 12 months. The increase in biceps and shoulder muscles showed a rapid incline in the $3^{\text {rd }}$ month and became almost normal in $6^{\text {th }}-12^{\text {th }}$ months.

Physiotherapy program is the recommended treatment option for patients with C5-7 OBPP at the first stage. This conservative treatment includes exercise, splint, and electrical stimulation. The purpose of conservative treatment is mainly to prevent contracture formation, hypoplasic arm development, dislocation of the radial head, and negative psychosocial consequences [1, $2,4,7]$. Although a spontaneous recovery can be seen in most of the cases, contracture formation in muscles and dislocation in shoulder and elbow may prevent functional recovery [7]. At this point, exercise program substantially contributes to the recovery of most of the patients.

However, there are no accurate data about the frequency, intensity, and time-planning of exercise programs. It is suggested that permanent disability may develop in some of the cases despite physiotherapy treatment [7]. This situation has raised more questions about the place of exercise in OBPP. Some authors suggested that exercises did not have much effect on recovery [4]. However, the other some have defended that intensive exercise program has a positive impact on recovery. However, they have still not clearly explained how this effect occurs [10].

When we examine the processes in the recovery of OBPP, we will observe that not only peripheral reconstruction but also central and spinal cord plasticity play a significant role in OBPP recovery $[6,8,15]$. It is hypothesized that physical exercises increase plasticity, especially, in the spinal cord and central area by inclining ependymal cell proliferation and thus ensure functional recovery $[11-13,16]$. Therefore, the representation of the body parts in the motor cortex can be altered after injury and during motor learning, and changes in the brain may be related to activity [15]. Plasticity increases due to the increased sensory input after exercises_ENREF_6(6). Cortical remodeling was shown to be increased after hand injuries through exercises. Hence, it was suggested that exercises are critical after peripheral nerve or central nervous system injuries [6]. Thus, our study looked at the effects of two different exercise programs for the upper brachial plexus lesions.

This study proved that there was no significant recovery difference between the groups in terms of time and degree and showed that intensive exercises did not have an additional contribution on peripheral nerve injuries, which meant that the frequency of the exercises did not have a significant effect on recovery. No complications developed in the patients during their follow-ups. However, further studies may be planned with some biochemical parameters as well as cranial and spinal cord imaging so that the effects of exercises on the recovery of cases with OBPP, especially, on the development of plasticity could be determined more accurately. Besides, further studies could be made on the effects of exercises on recovery with different intensity and duration as well as different frequencies.

\section{Clinical Messages}

1. Exercises positively affect recovery rate and results and prevent possible complications that may occur in cases with OBPP.

2. Intensive exercises did not have an additional contribution on peripheral nerve injuries, which means that the frequency of the exercises that the patients have daily did not have a significant effect on recovery.

Conflict of Interest: The authors declare no conflict of interest.

Financial Disclosure: The authors declared that this study has received no financial support.

Authorship Contributions: Concept - N.S.; Design - N.S.; Supervision - N.S., A.Y.K.; Materials - N.S., A.Y.K.; Data collection \&/ or processing - N.S., A.Y.K.; Analysis and/or interpretation - N.S., A.Y.K.; Writing - N.S., A.Y.K.; Critical review - N.S., A.Y.K.

\section{REFERENCES}

1. Yang LJ. Neonatal brachial plexus palsy-management and prognostic factors. Semin Perinatol 2014;38:222-34. [CrossRef]

2. Chauhan SP, Blackwell SB, Ananth CV. Neonatal brachial plexus palsy: Incidence, prevalence, and temporal trends. Semin Perinatol 2014;38:210-8. [CrossRef]

3. Backe B, Magnussen EB, Johansen OJ, Sellaeg G, Russwurm H. Obstetric brachial plexus palsy: A birth injury not explained by the known risk factors. Acta Obstet Gynecol Scand 2008;87:1027-32. [CrossRef]

4. Bahm J, Ocampo-Pavez C, Disselhorst-Klug C, Sellhaus B, Weis J. Obstetric brachial plexus palsy: Treatment strategy, long-term results, and prognosis. Dtsch Arztebl Int 2009;106:83-90.

5. Evans-Jones G, Kay SP, Weindling AM, Cranny G, Ward A, Bradshaw 
A, et al. Congenital brachial palsy: Incidence, causes, and outcome in the United Kingdom and republic of Ireland. Arch Dis Child Fetal Neonatal Ed 2003;88:F185-9. [CrossRef]

6. Strömbeck C, Krumlinde-Sundholm L, Remahl S, Sejersen T. Longterm follow-up of children with obstetric brachial plexus palsy I: Functional aspects. Dev Med Child Neurol 2007;49:198-203. [CrossRef]

7. Zafeiriou DI, Psychogiou K. Obstetrical brachial plexus palsy. Pediatr Neurol 2008;38:235-42. [CrossRef]

8. Buesch FE, Schlaepfer B, de Bruin ED, Wohlrab G, Ammann-Reiffer C, Meyer-Heim A, et al. Constraint-induced movement therapy for children with obstetric brachial plexus palsy: Two single-case series. Int J Rehabil Res 2010;33:187-92. [CrossRef]

9. Smith NC, Rowan P, Benson LJ, Ezaki M, Carter PR. Neonatal brachial plexus palsy. Outcome of absent biceps function at three months of age. J Bone Joint Surg Am 2004;86-A:2163-70. [CrossRef]

10. Terzis JK, Papakonstantinou KC. Management of obstetric brachial plexus palsy. Hand Clin 1999;15:717-36.
11. Asensio-Pinilla E, Udina E, Jaramillo J, Navarro X. Electrical stimulation combined with exercise increase axonal regeneration after peripheral nerve injury. Exp Neurol 2009;219:258-65. [CrossRef]

12. Foret A, Quertainmont R, Botman O, Bouhy D, Amabili P, Brook G, et al. Stem cells in the adult rat spinal cord: Plasticity after injury and treadmill training exercise. J Neurochem 2010;112:762-72. [CrossRef]

13. Kao T, Shumsky JS, Murray M, Moxon KA. Exercise induces cortical plasticity after neonatal spinal cord injury in the rat. J Neurosci 2009;29:7549-57. [CrossRef]

14. Bae DS, Waters PM, Zurakowski D. Correlation of pediatric outcomes data collection instrument with measures of active movement in children with brachial plexus birth palsy. J Pediatr Orthop 2008;28:58492. [CrossRef]

15. Strömbeck C, Remahl S, Krumlinde-Sundholm L, Sejersen T. Longterm follow-up of children with obstetric brachial plexus palsy II: Neurophysiological aspects. Dev Med Child Neurol 2007;49:204-9. [CrossRef]

16. Molnar GE, Alexander MA. Pediatric Rehabilitation. Philadelphia, PA: Hanley and Belfus; 1999. 